\title{
CDISC SDTM PK Unit of Measure Gram Weight Terminology
}

National Cancer Institute

\section{Source}

National Cancer Institute. CDISC SDTM PK Unit of Measure Gram Weight Terminology. NCI Thesaurus. Code C128684.

Terminology associated with the PK unit of measure gram weight codelist of the Clinical Data Interchange Standards Consortium (CDISC) Study Data Tabulation Model (SDT M). 